\title{
SOFTWARE EDUCATIVO PARA UNIVERSITÁRIOS SOBRE PREVENÇÃO DE ACIDENTES DE TRÂNSITO
}

ELAINE PASQUALINI

SANDRA REGINA GIMENIZ-PASCHOAL

\section{RESUMO}

Diante do elevado número de acidentes de trânsito (AT), o objetivo deste trabalho foi programar, aplicar e avaliar um software educativo para universitários sobre prevenção de AT - velocidade. Participaram das atividades 46 graduandos do curso de Análise de Sistemas de uma faculdade: 24 do grupo experimental (GE) e 22 do grupo controle (GC). Foram criados o software educativo e um programa de computador para armazenar dados. Todos os alunos realizaram o pré e o pós-teste, sendo que o GE usou o software e foi aplicado follow up após seis meses. Verificou-se que o GE apresentou aumento significativo do número de respostas corretas no pós-teste e follow up, e não foi significativa a diferença do GC. Concluiu-se que o software educativo tem bom potencial para ampliar conhecimentos dos universitários sobre AT.

PALAVRAS-CHAVE SOFTWARE EDUCATIVO - TECNOLOGIA EDUCACIONAL - PREVENÇÃO DE ACIDENTES DE TRÂNSITO • ENSINO SUPERIOR. 


\section{SOFTWARE EDUCATIVO PARA UNIVERSITARIOS SOBRE PREVENCIÓN DE ACCIDENTES DE TRÁFICO \\ RESUMEN}

Frente al elevado número de accidentes de tráfico (AT), el objetivo de este trabajo fue el de programar, aplicar y evaluar un software educativo para universitarios sobre prevención de AT - velocidad. Participaron en las actividades 46 graduandos del curso de Análisis de Sistemas de una facultad: 24 del grupo experimental (GE) y 22 del grupo control (GC). Se creó el software educativo y un programa de computadora para almacenar datos. Todos los alumnos realizaron el pre y el post tests, y el GE utilizó el software y aplicó un follow up después de seis meses. Se verificó que el GE presentó un significativo aumento del número de respuestas correctas en el post test y el follow up, mientras que no fue significativa la diferencia del GC. Se concluyó que el software educativo posee un buen potencial para ampliar los conocimientos de los universitarios sobre AT.

palabras clave software educativo - tecnología educacional • PREVENCIÓN DE ACCIDENTES DE TRÁFICO • EDUCACIÓN SUPERIOR.

\section{EDUCATIONAL SOFTWARE FOR UNIVERSITY STUDENTS REGARDING THE PREVENTION OF TRAFFIC ACCIDENTS}

ABSTRACT

Confronted with the increased number of traffic accidents (TA), the purpose of the present study was to program, apply and evaluate a piece of educational software for university students regarding the prevention of TA - speed. Forty-six graduates of Systems Analysis participated in the activities: 24 in the experimental group (EG) and 22 in the control group (CG). The educational software and a computer program to store the data were created. All students performed pre- and post-tests, and the EG used the software and also did the follow-up after six months. It appeared that the EG had an increased number of correct responses in the post-test and the followup, but it was not significantly different from the CG. It was concluded that the educational software has good potential for increasing knowledge of university students regarding TA.

KEYWORDS EDUCATIONAL SOFTWARE - EDUCATIONAL TECHNOLOGY • TRAFFIC ACCIDENT PREVENTION • HIGHER EDUCATION. 


\section{INTRODUÇÃO}

A cada ano, no mundo, quase 1,2 milhão de pessoas morrem e 20 a 50 milhões ficam feridas ou incapacitadas como resultado de acidentes de trânsito (AT). Para pessoas com menos de 44 anos, o acidente de trânsito é a principal causa de morte e invalidez (WILSON et al., 2010).

No Brasil, ocorrem, ao ano, aproximadamente 33 mil óbitos e cerca de 400 mil ficam feridos ou inválidos em consequência de acidentes de trânsito, sendo 75\% deles causados por falha humana (SÃO PAULO, 2009). Esses acidentes são os principais responsáveis pela mortalidade de jovens (ANDRADE et al., 2003; ABREU, 2006).

Nesse contexto, o número de AT pode representar alterações na economia do país, em função da morte de jovens correspondentes a uma parcela da população economicamente ativa. Além disso, para os acidentados, podem ocorrer sequelas e diversos problemas, entre os quais os escolares, desde falta às aulas até dificuldades que impedem a conclusão do curso.

No Código de Trânsito Brasileiro, o capítulo 6 trata da educação para o trânsito. Seu artigo 76 estabelece que a edu- 
cação para o trânsito poderá ser promovida em todos os níveis escolares, incluindo o superior, por meio de

[...] planejamento e ações coordenadas entre os órgãos e entidades do Sistema Nacional de Trânsito e de Educação, da União, dos Estados, do Distrito Federal e dos Municípios, nas respectivas áreas de atuação. (PAULO, 2006, p. 45)

Uma alternativa é a criação de ações educativas para tentar reduzir o número de AT (SILVA; DAGOSTIM, 2006), por meio de softwares educativos, dentro de uma abordagem pedagógica (VALENTE, 1993).

A instrução auxiliada por computador é uma dessas ações educativas que teve sua origem na instrução programada, proposta por Skinner no final dos anos 1950 e início dos anos 1960. A instrução programada tem como características o ensino individualizado e a divisão do conteúdo em pequenas unidades de ensino de forma lógica e sequencial. Cada unidade é finalizada por uma revisão que pode conter questões com respostas curtas, de múltipla escolha, de preenchimento de lacunas, entre outras, sendo apresentado um feedback imediato ao aluno. Se atingir o objetivo proposto, ele passará para a unidade seguinte; caso contrário, é aconselhado a rever novamente a unidade (BULHÕES, 2008). Outro aspecto da instrução programada é que os alunos sabem quais são os objetivos que devem alcançar (CROSBIE; KELLY, 1993).

Pesquisas realizadas por Kinsner e Pear (1988), Crosbie e Kelly (1993), Pear e Novak (1996), Koen (2001), Crone-Todd et al. (2007) e Springer e Pear (2008) apontam ganhos de aprendizagem e satisfação de universitários, indicando resultados positivos com o uso de softwares educativos com base nesse método de ensino. No Brasil, os trabalhos encontrados foram poucos, sobretudo no ensino superior.

Dessa forma, o objetivo desse trabalho foi programar, aplicar e avaliar um software educativo para universitários, envolvendo a temática de prevenção de acidentes de trânsito, especificamente sobre velocidade, usando a instrução auxiliada por computador. 


\section{MÉTODO}

Este estudo foi submetido ao Comitê de Ética em Pesquisa da Universidade Estadual Paulista "Júlio de Mesquita Filho" (Unesp), campus de Marília, e aprovado sob Parecer n. 0103/2011.

A pesquisa foi realizada em faculdade pública em uma cidade do interior do estado de São Paulo com cerca de 110.000 habitantes. Foram utilizados os laboratórios de informática e as salas de aula.

A escolha do local foi em razão da aceitação da instituição em colaborar com a pesquisa, mais especificamente do curso de Análise e Desenvolvimento de Sistemas.

A ação educativa contou com 46 alunos de primeiro ano do curso, que concordaram em participar e assinaram o termo de consentimento. Foram escolhidos os alunos de primeiro ano por serem, em geral, mais jovens e estarem na idade em que se obtém a carteira de habilitação. Além disso, a designação de qual turma comporia cada grupo foi feita por uma seleção aleatória.

Portanto, 24 alunos de uma turma do período da noite foram designados para o grupo experimental e 22 alunos de uma turma do período da manhã, para o grupo controle. Não foi realizado sorteio entre os alunos nas duas turmas a fim de decidir em qual grupo ficariam para evitar comunicação entre eles, o que poderia afetar os resultados da pesquisa.

O grupo controle tinha as seguintes características:

- a maioria era do sexo masculino (13 alunos, 59\%);

- quanto à faixa etária, os alunos estavam distribuídos da seguinte forma: de 18 a 21 anos, 11 alunos (50\%); de 22 a 24 anos, dois alunos (9\%); de 25 a 27 anos, dois alunos (9\%); e acima de 27 anos, sete alunos (32\%);

1 Foi utilizado o Critério de Classificação Econômica Brasil de 2003 para identificação da classe social. (ASSOCIAÇÃO BRASILEIRA DE EMPRESAS DE PESQUISA - ABEP, 2003)
- quanto ao nível socioeconômico dos alunos, em B2 ${ }^{1}$ havia dois alunos (9\%); em C, dez alunos (45\%); em D, nove alunos (41\%); e, em E, um aluno (5\%);

- os tempos de habilitação foram: menos de um ano, quatro alunos (18,18\%); um ano, um aluno (4,55\%); de dois a nove anos, cinco alunos (22,73\%); acima de nove anos, cinco alunos (22,73\%); e sem habilitação, sete alunos $(31,82 \%)$. 
Os alunos do grupo experimental apresentavam as seguintes características:

- a maioria era do sexo masculino, neste caso, 21 alunos (88\%);

- quanto à faixa etária, os alunos estavam distribuídos da seguinte forma: de 18 a 21 anos, 16 alunos (67\%); de 22 a 24 anos, dois alunos (8\%); de 25 a 27 anos, dois alunos (8\%); e, acima de 27 anos, quatro alunos (17\%);

- quanto ao nível socioeconômico dos alunos, em $\mathrm{B}^{2}$ havia dois alunos (8\%); em C, 12 alunos (50\%); em D, nove alunos (38\%); e, em E, um aluno (4\%);

- o tempo de habilitação, neste grupo, apresenta a seguinte distribuição: menos de um ano, dois alunos (8\%); um ano, dois alunos (8\%); de dois a nove anos, seis alunos (25\%); mais de nove anos, três alunos (12\%); e sem habilitação, 11 alunos (46\%).

As amostras dos grupos controle e experimental da faculdade foram submetidas a uma análise estatística por meio do software SPSS para verificar a equivalência das distribuições. Foram utilizados os testes Mann-Whitney e de Fisher para as variáveis idade, tempo de habilitação, sexo e nível socioeconômico. A única variável que não possuía equivalência era o sexo.

\section{MATERIAIS E INSTRUMENTOS}

Para a realização da pesquisa, foram utilizados:

- termo de consentimento livre e esclarecido;

- questionário inicial elaborado com base nos dados apresentados pelo Departamento Nacional de Trânsito (Denatran), que teve como objetivo levantar subsídios para elaboração do software. Esse instrumento possuía perguntas fechadas e abertas, indagando se já ocorreram acidentes para caracterizar o envolvimento em AT, quais informações os alunos gostariam de ter em relação ao trânsito, se gostariam de usar um software educativo sobre AT, etc.;

- computadores e impressoras;

- linguagens de programação Php e JavaScript e a linguagem de marcação HTML para acesso à Internet.
2 Foi utilizado o Critério de Classificação Econômica Brasil de 2003 para identificação da classe social. (ABEP, 2003). 
Essas linguagens foram utilizadas para a criação do software;

- banco de dados MySQL para armazenar os dados dos alunos e os resultados da ação educativa;

- Internet com qualquer navegador para acessar o programa de computador;

- planilha eletrônica para gerar gráficos;

- software Statistical Package for the Social Sciences (SPSS);

- programa de computador desenvolvido para armazenar dados das instituições, dos alunos, do software educativo, dos questionários, dos relatórios, etc.;

- roteiro das unidades: foram criadas oito unidades de ensino, que correspondem ao software educacional;

- questionários pré e pós-teste e follow-up: as 15 questões objetivas dos pré e pós-testes e follow-up foram elaboradas com base no software educativo e criadas por meio da revisão da literatura sobre o assunto. $\mathrm{O}$ pré-teste, o pós-teste e o follow-up são idênticos, para se comparar o número de acertos das questões antes e depois da ação educativa. Os alunos não podem responder novamente o mesmo questionário, pois o programa de computador permite o acesso apenas uma vez;

- questionário sobre as opiniões dos alunos a respeito do programa de computador e do software educativo, criado de acordo com Valente (1999), cuja finalidade foi identificar as opiniões dos alunos sobre o programa de computador e o software educativo. Este questionário possui dez questões objetivas, sendo que em oito delas os alunos poderiam descrever, caso desejassem, suas opiniões e sugestões.

\section{PROCEDIMENTOS}

Os procedimentos deste estudo consistiram nas etapas de desenvolvimento do software educativo (unidades de ensino) e do programa de computador, aplicação e avaliação da ação educativa. 


\section{DESENVOLVIMENTO DAS UNIDADES DE ENSINO}

Para o desenvolvimento foi estabelecido um método de acordo com Maeda et al. (2005) e Filatro (2008), composto pelas etapas:

- análise: foi realizada uma revisão por meio da literatura e criado um questionário inicial para levantamento de subsídios para identificar as principais causas de AT, possibilidades de uso de um software educativo, etc. O questionário foi aplicado em 91 alunos de quatro cursos da faculdade, selecionados aleatoriamente, e cada estudante recebeu uma cópia em papel do questionário para responder;

- projeto: abrangeu a definição de objetivos, questionários, feedbacks, conteúdos e o sequenciamento dos mesmos, para a criação do roteiro (storyboard) com base nos dados coletados na análise;

- desenvolvimento: compreendeu a codificação do roteiro nas linguagens de programação Php e JavaScript, juntamente com a linguagem de marcação HTML.

Na etapa de projeto, os procedimentos foram elaborados com base na instrução programada, de acordo com Catania (1999), Zanotto (2000), Teixeira (2002), Bernardes (2002) e Hübner e Marinotti (2004):

- ensino individualizado e ritmo de cada aluno;

- divisão do conteúdo em unidades de ensino, de forma lógica e sequencial. Uma unidade de aprendizagem é uma unidade elementar que contém os itens básicos para se chegar aos objetivos da aprendizagem. Para Filatro (2008), a granularidade (tamanho) de uma unidade de aprendizagem não pode ser subdividida em partes e perder seu significado, mas também não pode ser extensa, pois deve ser modular;

- o aluno não pode ir para a unidade seguinte se não atingir os objetivos que foram propostos;

- questionário ou revisão, ao final de cada unidade, com questões ou exercícios de forma compatível com o que o aluno aprendeu; 
- feedback imediato das questões que os alunos têm para responder;

- apresentação de conteúdos aos alunos dos mais simples aos mais complexos;

- descrição dos objetivos aos alunos, identificando quais eles devem alcançar. Segundo Vargas (1974), um objetivo deve ser explicitado ao aluno em termos do que se espera dele ao final de uma unidade de ensino, ou seja, o que ele deve ser capaz de fazer, com um nível de critério ou desempenho aceitável;

- aproximação do conteúdo das unidades à realidade, para mostrar aos alunos que eles podem usar no cotidiano.

\section{DESENVOLVIMENTO DO PROGRAMA DE COMPUTADOR}

Para o armazenamento de dados dos participantes, instituições de ensino, unidades de ensino, etc., um programa de computador foi desenvolvido e adotou-se um método, segundo a literatura sobre engenharia de software, abrangendo várias etapas, de acordo com Peters e Pedrycz (2001) e Pressman (2002):

- $\quad$ especificação de requisitos - identificação das necessidades do programa de computador, que consistiu em levantar dados por meio da literatura sobre pré e pós-teste, grupos controle e experimental, relatórios que seriam criados para os resultados da pesquisa, entre outros;

- especificação do projeto - descrição das funcionalidades do sistema, isto é, quais as opções que o programa necessitou, tais como cadastro de alunos, instituições, questões, etc. Também foi criado o projeto de interface, no qual os menus, janelas, botões e links foram planejados;

- implementação - codificação do programa nas linguagens de programação Php e Javacript e utilização da linguagem de marcação de página HTML para uso na Internet e no banco de dados MySQL;

- testes - identificação dos possíveis erros no programa e o comportamento de suas funções; 
- manutenção - modificações no programa, em função dos erros encontrados.

\section{APLICAČ̃̃O DA AÇÃO EDUCATIVA}

Com a concordância dos professores quanto ao uso de suas aulas para aplicação da ação educativa sobre AT com o tema velocidade, foi apresentada a proposta aos participantes, que precisariam fazer um cadastro com alguns dados, como sexo, data de nascimento, login, senha, etc., e, caso concordassem em participar da pesquisa, deveriam assinar o termo de consentimento.

Inicialmente, foram dadas as instruções a respeito do acesso ao site (endereço, uso de login e senha), objetivo, método de ensino (sequência da ação educativa, questionários, leitura de textos, etc.) e tempo aproximado de duração. Essas informações também constam do programa de computador.

A ação foi aplicada no mesmo dia, sendo no período da manhã para os alunos do grupo controle e à noite para os alunos do grupo experimental.

\section{a. Aplicação da ação com os alunos do grupo controle}

No laboratório de informática, os participantes do grupo controle fizeram o pré-teste (identificação dos conhecimentos que tinham sobre o tema) e assistiram a um vídeo com seis minutos de duração sobre o futuro das tecnologias da informação. Escolheu-se esse tema pelo fato de estar relacionado ao curso deles e por não envolver assuntos sobre AT, que poderiam influenciar os resultados do pós-teste. Depois da apresentação do vídeo, os alunos realizaram o pós-teste, finalizando a aplicação, com a duração máxima de 1 hora e 30 minutos.

Foi explicado, então, o motivo pelo qual eles não tiveram acesso às unidades de ensino e pertenciam ao grupo controle. A pesquisadora agradeceu a todos pela colaboração, colocando-se à disposição para quaisquer esclarecimentos, bem como para obterem impressas as unidades de ensino.

\section{b. Aplicação da ação com os alunos do grupo experimental \\ Compareceram ao laboratório 24 alunos, mas apenas 20 concluíram as atividades, pelo fato de faltar energia elétrica}


logo no início da aplicação e voltar depois de meia hora. Os quatro alunos saíram e, quando a energia foi restabelecida, não retornaram ao local. Os demais alunos fizeram o pré-teste e, em seguida, receberam as unidades de ensino. A última parte consistiu na aplicação de um questionário sobre os conhecimentos adquiridos (pós-teste) e eles também responderam um questionário a respeito de suas opiniões sobre o programa de computador e as unidades.

Devido ao problema ocorrido com a energia elétrica, o tempo total utilizado para a aplicação foi de três horas.

\section{c. Aplicação do follow-up na faculdade}

Transcorridos seis meses da ação educativa, foram aplicados os mesmos questionários de pré e pós-teste para o grupo experimental da faculdade, com o objetivo de fazer um acompanhamento (follow-up). Os alunos foram avisados e, no dia da aplicação, compareceram 15 (75\%), do total de 20.

\section{AVALIAÇÃO DA AÇÃO EDUCATIVA}

Para avaliar a ação educativa, foram gerados relatórios das respostas dos alunos, por meio do programa de computador. Como ferramenta de apoio para a criação de gráficos, utilizaram-se uma planilha eletrônica e o software estatístico SPSS.

\section{RESULTADOS}

Descrevem-se neste item os resultados obtidos na programação, aplicação e avaliação do software educativo.

QUESTIONÁRIO INICIAL PARA LEVANTAMENTO DE SUBSÍDIOS PARA ELABORAÇÃO DO SOFTWARE EDUCATIVO

Os alunos responderam que usariam um software educativo sobre trânsito porque: seria útil para prevenção de acidentes (78 alunos, ou 86\%); ajudaria a conscientizar mais as pessoas (24 alunos, ou 31\%); esclareceria dúvidas referentes ao trânsito (7 alunos, ou 9\%); seria interessante e uma forma inovadora de aprender sobre trânsito (quatro alunos, ou 5\%); ajudaria a mostrar as falhas humanas (quatro alunos, ou 5\%), entre outros. 
As principais necessidades em relação ao trânsito foram: saber sobre sinalização e placas (21 alunos, ou 23\%); conhecimento a respeito de leis, multas e penalizações (11 alunos, ou $12 \%$ ); entre outras.

Quando questionado aos alunos que possuíam a $\mathrm{CNH}$ se já tinham sido multados alguma vez, 29 (38\%) responderam afirmativamente, sendo que o principal motivo da multa foi excesso de velocidade (oito alunos, ou $28 \%$ ), seguido por estacionar em local proibido (cinco alunos, ou 17\%).

Sofreram algum tipo de acidente de trânsito, como condutores ou não, 40 alunos (44\%). As causas mais frequentes foram desrespeito às leis de trânsito (oito alunos, ou 20\%), consumo de bebida alcoólica (sete alunos, ou 18\%) e excesso de velocidade (seis alunos, ou 15\%). Para Andrade et al. (2003) e Marín-Leon e Vizzotto (2003), as principais causas de AT entre jovens são dirigir em alta velocidade, dirigir alcoolizado e avançar o sinal fechado.

Nesse contexto, pelos resultados do questionário inicial aplicado, o motivo mais frequente de multas foi por excesso de velocidade. E, segundo as pesquisas identificadas por meio de busca da literatura, a velocidade é apontada como um dos principais fatores para acidentes. Com os dados obtidos, optou-se em trabalhar com o tema velocidade.

\section{UNIDADES DE ENSINO}

Uma das características presentes no roteiro foi a utilização de questões objetivas para verificar se a finalidade foi atingida no final de cada unidade, sendo que o aluno somente poderia ir para a unidade seguinte se acertasse todas as questões. Também procurou-se dar às respostas corretas do aluno mensagens como: "Muito bem, passe para a unidade seguinte!". Se o aluno não conseguisse atingir o objetivo proposto, ele era aconselhado a rever a unidade. O roteiro foi composto por textos, ilustrações e animações.

Segundo Piva, Freitas e Miskulin (2009), o material didático é elaborado de acordo com os objetivos de ensino e alguns aspectos podem ser seguidos na confecção de textos, como:

- linguagem clara ou explicativa para facilitar a compreensão, sem jargões, palavras dificeis e desnecessárias, 
como: unidade 7 - "A impulsividade pode ser definida como tomada de decisão sem a consideração das variáveis envolvidas em uma dada situação". Em seguida, explica-se: "Por exemplo, brigar com uma pessoa que você acha que é culpada de algo, sem levar em conta se ela realmente é culpada ou inocente";

- linguagem de conversação amigável e voltada para o informal, como: unidade 3 - "Aparece na via uma mulher ou homem bonito e o motorista se distrai!!”;

- convites, questionamentos ou perguntas, como no caso: unidade 3 - "Por que alguns motoristas ultrapassam o limite de velocidade permitido?”;

- uso de pronomes pessoais, como nós, você, para demonstrar aproximação do leitor com o texto, como: unidade 3 - "Temos alguns exemplos de causas de acidentes entre os jovens brasileiros [...]";

- referências para leituras: em todas as unidades houve preocupação em apresentar ao aluno as referências usadas, para que ele pudesse ler as fontes em outro momento;

- ativação do conhecimento prévio do aluno. É importante lembrar ao aluno o conhecimento que já possui e que será utilizado para um novo aprendizado, revendo o conteúdo, como no caso: unidade 5 - "[...] fórmula da velocidade, distância e tempo, estudada no ensino médio";

- colocação do conteúdo em uma sequência em que primeiro aparecem os conceitos e as partes que sensibilizam. Foram colocados, no início das unidades, alguns conceitos, número de mortos em AT para sensibilizar o aluno.

As ilustrações foram usadas com ou sem textos para possibilitar aos alunos um meio visual e facilitador de aprendizagem. Conforme Sancho (1998), as ilustrações têm uma boa aceitação, especialmente entre os jovens e, por isso, foram inseridas nas unidades.

A maioria das figuras foi criada para esse trabalho e algumas foram obtidas por meio de fontes citadas no próprio 
roteiro, com permissão do seu uso. Em todo o roteiro, foi empregado o mesmo estilo de ilustração (desenho caricaturado).

Foram usadas duas animações: uma sobre velocidade, distância e tempo de chegada a um destino; e a outra sobre velocidade e as distâncias envolvidas na parada de um veículo.

Para atender às etapas de análise e projeto, foram definidas oito unidades, como mostra o Quadro 1, com o número da unidade, nome e o objetivo para o aluno.

QUADRO 1 - Unidades, objetivos e motivo da escolha dos conteúdos

\begin{tabular}{|c|c|c|}
\hline $\mathrm{N}^{\circ}$. & NOME DA UNIDADE & OBJETIVO PARA OS ALUNOS \\
\hline 1 & Conceitos de acidente e acidente de trânsito & $\begin{array}{l}\text { Você deverá definir os conceitos de acidente e acidente de } \\
\text { trânsito }\end{array}$ \\
\hline 2 & $\begin{array}{l}\text { Número de mortos e problemas ocasionados } \\
\text { aos jovens com os AT }\end{array}$ & $\begin{array}{l}\text { Você deverá comparar o número de mortos em AT no Brasil } \\
\text { em alguns anos e identificar os problemas ocasionados, } \\
\text { principalmente entre os jovens }\end{array}$ \\
\hline 3 & $\begin{array}{l}\text { Principais causas de AT no Brasil e alguns } \\
\text { fatores que levam os motoristas a dirigir em } \\
\text { alta velocidade }\end{array}$ & $\begin{array}{l}\text { Você deverá ser capaz de identificar as principais causas de AT } \\
\text { no Brasil e alguns fatores que levam motoristas a dirigir em alta } \\
\text { velocidade }\end{array}$ \\
\hline 4 & Limites de velocidade, suas leis e penalidades & $\begin{array}{l}\text { Você deverá identificar os limites de velocidade nos tipos de } \\
\text { vias, as penalidades existentes e as pontuações na CNH }\end{array}$ \\
\hline 5 & Quem tem pressa? & $\begin{array}{l}\text { Você deverá comparar a velocidade máxima permitida por lei } \\
\text { com a velocidade em excesso em uma determinada distância e } \\
\text { o tempo gasto usando as duas velocidades }\end{array}$ \\
\hline 6 & $\begin{array}{l}\text { Distâncias envolvidas na parada de um } \\
\text { veículo }\end{array}$ & $\begin{array}{l}\text { Você deverá ser capaz de conceituar distância percorrida } \\
\text { durante o tempo de reação, distância de frenagem e distância } \\
\text { total de parada }\end{array}$ \\
\hline 7 & Impulsividade e educação para o trânsito & $\begin{array}{l}\text { Você deverá conceituar impulsividade e identificar a importância } \\
\text { da educação para o trânsito }\end{array}$ \\
\hline 8 & $\begin{array}{l}\text { Considerações finais: comportamento no } \\
\text { trânsito: conhecimento, prática e atitude }\end{array}$ & $\begin{array}{l}\text { Você deverá definir conhecimento, prática e atitude e identificar } \\
\text { alguns tipos de comportamentos de motoristas no trânsito }\end{array}$ \\
\hline
\end{tabular}

Fonte: Elaboração das autoras.

\section{AÇÃO EDUCATIVA - ALUNOS DO GRUPO CONTROLE - PRÉ E PÓS-TESTE}

Os resultados da aplicação do pré e pós-teste (de 15 questões cada um) aos alunos pertencentes ao grupo controle (22 alunos) são apresentados na Tabela 1. 
TABELA 1 - Número e porcentagem de acertos do pré e pós-teste, aplicados aos alunos pertencentes ao grupo controle

\begin{tabular}{|c|c|c|c|c|c|c|c|c|c|}
\hline \multirow{2}{*}{ ALUNO } & \multicolumn{2}{|c|}{ PRÉ-TESTE } & \multicolumn{2}{|c|}{ PÓS-TESTE } & \multirow{2}{*}{ ALUNO } & \multicolumn{2}{|c|}{ PRÉ-TESTE } & \multicolumn{2}{|c|}{ PÓS-TESTE } \\
\hline & $n$ & $\%$ & $n$ & $\%$ & & $n$ & $\%$ & $n$ & $\%$ \\
\hline 1 & 10 & 67 & 8 & 53 & 12 & 11 & 73 & 11 & 73 \\
\hline 2 & 6 & 40 & 5 & 33 & 13 & 9 & 60 & 9 & 60 \\
\hline 3 & 5 & 33 & 6 & 40 & 14 & 6 & 40 & 4 & 27 \\
\hline 4 & 7 & 47 & 8 & 53 & 15 & 6 & 40 & 7 & 47 \\
\hline 5 & 3 & 20 & 5 & 33 & 16 & 6 & 40 & 4 & 27 \\
\hline 6 & 10 & 67 & 8 & 53 & 17 & 11 & 73 & 11 & 73 \\
\hline 7 & 9 & 60 & 9 & 60 & 18 & 5 & 33 & 6 & 40 \\
\hline 8 & 7 & 47 & 7 & 47 & 19 & 6 & 40 & 6 & 40 \\
\hline 9 & 8 & 53 & 9 & 60 & 20 & 8 & 53 & 8 & 53 \\
\hline 10 & 9 & 60 & 7 & 47 & 21 & 10 & 67 & 10 & 67 \\
\hline 11 & 5 & 33 & 6 & 40 & 22 & 8 & 53 & 8 & 53 \\
\hline
\end{tabular}

Fonte: Dados da pesquisa (elaboração das autoras)

Na Tabela 1, verificam-se aumento e diminuição do número de acertos do pré para o pós-teste em no máximo duas questões, e nove alunos (41\%) do grupo controle mantiveram-se com o mesmo número de acertos.

A alternativa "Não sei" foi assinalada por nove alunos (41\%), para algumas questões, tanto no pré como no pós-teste.

O aluno $\mathrm{n}^{\circ} 12$ acertou 11 questões no pré e no pós-teste. Sua $\mathrm{CNH}$ correspondia à categoria $\mathrm{AD}$ (condutor de veículo motorizado utilizado no transporte de passageiros, cuja lotação exceda a oito lugares, como ônibus e micro-ônibus, além de poder dirigir motocicleta). Segundo o Detran-SP (SÃO PAULO, 2001), para a obtenção dessa categoria, o motorista deve fazer um curso de direção defensiva especial, além de uma prova prática específica. Nesse contexto, tal motorista provavelmente poderá ter mais conhecimentos do que um outro que tenha um tipo simples de $\mathrm{CNH}$, como as categorias A (condutor de veículo motorizado de duas ou três rodas) ou $\mathrm{B}$ (condutor de veículo motorizado de passeio).

$\mathrm{O}$ aluno $\mathrm{n}^{\circ} 17$, que também acertou 11 questões nos dois testes, possuía a categoria $\mathrm{AB}$ e tinha 9 anos de habilitação.

A média aritmética no pré-teste foi de 7,5 e o desvio padrão foi de 2,2, bem próximos das estatísticas do pós-teste, em que a média foi 7,4 e o desvio padrão, 2,0. 
Para verificar se havia diferença estatisticamente significante entre as médias do pré-teste e pós-teste, aplicou-se o teste estatístico T-Student por meio do software SPSS e foi constatado que não havia $(p>0,05)$.

\section{AÇÃO EDUCATIVA - ALUNOS DO GRUPO EXPERIMENTAL - PRÉ E PÓS-TESTE}

Os resultados da aplicação do pré e pós-teste (de 15 questões cada um) aos alunos pertencentes ao grupo experimental da faculdade (20 alunos) são apresentados na Tabela 2.

TABELA 2 - Número e porcentagem de acertos do pré e pós-teste, aplicados aos alunos pertencentes ao grupo experimental

\begin{tabular}{|c|c|c|c|c|c|c|c|c|c|}
\hline \multirow{2}{*}{ ALUNOS } & \multicolumn{2}{|c|}{ PRÉ-TESTE } & \multicolumn{2}{|c|}{ PÓS-TESTE } & \multirow{2}{*}{ ALUNOS } & \multicolumn{2}{|c|}{ PRÉ-TESTE } & \multicolumn{2}{|c|}{ PÓS-TESTE } \\
\hline & $n$ & $\%$ & $n$ & $\%$ & & $n$ & $\%$ & $n$ & $\%$ \\
\hline 1 & 6 & 40 & 12 & 80 & 11 & 9 & 60 & 14 & 93 \\
\hline 2 & 9 & 60 & 13 & 87 & 12 & 11 & 73 & 13 & 87 \\
\hline 3 & 8 & 53 & 12 & 80 & 13 & 10 & 67 & 9 & 60 \\
\hline 4 & 8 & 53 & 13 & 87 & 14 & 6 & 40 & 10 & 67 \\
\hline 5 & 7 & 47 & 11 & 73 & 15 & 8 & 53 & 12 & 80 \\
\hline 6 & 9 & 60 & 12 & 80 & 16 & 6 & 40 & 13 & 87 \\
\hline 7 & 6 & 40 & 9 & 60 & 17 & 4 & 27 & 8 & 53 \\
\hline 8 & 8 & 53 & 11 & 73 & 18 & 9 & 60 & 12 & 80 \\
\hline 9 & 8 & 53 & 13 & 87 & 19 & 10 & 67 & 14 & 93 \\
\hline 10 & 8 & 53 & 13 & 87 & 20 & 8 & 53 & 11 & 73 \\
\hline
\end{tabular}

Fonte: Dados da pesquisa (elaboração das autoras).

Na Tabela 2, observa-se que apenas o aluno $\mathrm{n}^{\circ} 13$ teve $\mathrm{o}$ número de acertos diminuído do pré para o pós-teste e isso ocorreu em apenas uma questão.

Dos alunos que fizeram o pré-teste, sete (35\%) marcaram a alternativa "não sei" para algumas questões, já no pós-teste, um aluno (5\%) marcou a referida alternativa.

A média aritmética do pré-teste do grupo experimental foi de 7,9 e o desvio padrão foi de 1,7, enquanto no pós-teste, a média foi 11,8 e o desvio padrão, 1,7. Aplicado o mesmo teste usado para o grupo controle, foi constatada diferença estatisticamente significante entre as médias do pré-teste e pós-teste $(p<0,05)$.

A média aritmética do pós-teste do grupo experimental aumentou em relação à média do pré-teste desse mesmo grupo. 


\section{AVALIAÇÃO DO PROGRAMA DE COMPUTADOR E DAS UNIDADES PELOS ALUNOS}

As tabelas 3, 4, 5 e 6 mostram a distribuição das respostas de avaliação dos alunos a respeito do programa de computador e das unidades de ensino.

TABELA 3 - Distribuição das respostas de avaliação dos alunos do grupo experimental a respeito do programa de computador e das unidades de ensino

\begin{tabular}{|c|c|c|c|c|c|c|c|c|c|c|}
\hline \multirow{2}{*}{ QUESTÃO } & \multicolumn{2}{|c|}{ МUITO вом } & \multicolumn{2}{|c|}{ BOM } & \multicolumn{2}{|c|}{ REGULAR } & \multicolumn{2}{|c|}{ DEFICIENTE } & \multicolumn{2}{|c|}{$\begin{array}{c}\text { MUITO } \\
\text { DEFICIENTE }\end{array}$} \\
\hline & $n$ & $\%$ & $n$ & $\%$ & $n$ & $\%$ & $n$ & $\%$ & $n$ & $\%$ \\
\hline $\begin{array}{l}\text { O que achou dos conteúdos } \\
\text { apresentados? }\end{array}$ & 3 & 15 & 16 & 80 & - & - & 1 & 5 & - & - \\
\hline $\begin{array}{l}\text { O que achou dos feedbacks } \\
\text { apresentados dos questionários? }\end{array}$ & 8 & 40 & 10 & 50 & 2 & 10 & - & - & - & - \\
\hline
\end{tabular}

Fonte: Dados da pesquisa (elaboração das autoras).

TABELA 4 - Distribuição das respostas dos alunos do grupo experimental a respeito da avaliação do programa de computador e das unidades de ensino

\begin{tabular}{|c|c|c|c|c|}
\hline \multirow{2}{*}{ QUESTÃO } & \multicolumn{2}{|c|}{ SIM } & \multicolumn{2}{|c|}{ NÃO } \\
\hline & $n$ & $\%$ & $n$ & $\%$ \\
\hline As questões estavam de acordo com os conteúdos apresentados & 20 & 100 & - & - \\
\hline O software apresentou facilidade de navegação & 19 & 95 & 1 & 5 \\
\hline Indicaria para outros alunos fazerem um curso neste formato & 20 & 100 & - & - \\
\hline Seus conhecimentos foram suficientes para acompanhar o curso & 18 & 90 & 2 & 10 \\
\hline O software apresentou instruções claras & 20 & 100 & - & - \\
\hline Os objetivos propostos pelo software foram atingidos & 20 & 100 & - & - \\
\hline
\end{tabular}

Fonte: Dados da pesquisa (elaboração das autoras)

Nas tabelas 5 e 6, os alunos podiam escolher mais de uma opção.

TABELA 5 - Distribuição das respostas dos alunos do grupo experimental sobre aspectos positivos das unidades de ensino, sendo que cada aluno poderia selecionar mais de um

\begin{tabular}{|c|c|c|}
\hline ASPECTOS POSITIVOS & $n$ & $\%$ \\
\hline Estou mais ciente dos problemas e perigos em correr em alta velocidade & 15 & 75 \\
\hline Despertou minha atenção quanto ao meu modo de dirigir & 7 & 35 \\
\hline $\begin{array}{l}\text { Identifiquei que posso melhorar alguns aspectos da minha maneira de dirigir, atitudes e } \\
\text { comportamentos, principalmente em relação ao excesso de velocidade }\end{array}$ & 6 & 30 \\
\hline $\begin{array}{l}\text { Importante para os motoristas universitários se conscientizarem porque grande parte dos } \\
\text { acidentes de trânsito ocorre entre jovens }\end{array}$ & 14 & 70 \\
\hline Aprendi informações sobre leis de trânsito que não sabia & 14 & 70 \\
\hline Identifiquei que o trânsito seguro é responsabilidade de todos & 11 & 55 \\
\hline $\begin{array}{l}\text { Identifiquei que as ações preventivas são importantes e podem diminuir o número de acidentes } \\
\text { a médio e longo prazos }\end{array}$ & 11 & 55 \\
\hline
\end{tabular}

Fonte: Dados da pesquisa (elaboração das autoras). 
TABELA 6 - Distribuição das respostas dos alunos do grupo experimental sobre aspectos negativos das unidades de ensino

\begin{tabular}{l|c:c}
\hline \multicolumn{1}{c}{ ASPECTOS NEGATIVOS } & $n$ & $\%$ \\
\hline Não esclarecer o método de ensino & 1 & 5 \\
\hline Não esclarecer os conteúdos de cada unidade de maneira clara & 1 & 5 \\
\hline Nenhum & 16 & 80 \\
\hline Outro aspecto: muito bom o curso, mas tem bastante texto & 2 & 10 \\
\hline
\end{tabular}

Fonte: Dados da pesquisa (elaboração das autoras).

\section{FOLLOW-UP DOS ALUNOS DO GRUPO EXPERIMENTAL}

Os dados da Tabela 7 mostram as porcentagens de acertos no pré-teste, pós-teste e follow-up dos alunos do grupo experimental. Foram considerados os alunos que responderam todos os questionários (pré, pós e follow-up).

TABELA 7 - Porcentagens de acertos no pré-teste, pós-teste e follow-up dos alunos do grupo experimental $(\mathrm{N}=15)$

\begin{tabular}{c|c:c:c}
\hline ALUNOS & PRÉ & PÓS & FOLLOW-UP \\
\hline $\mathbf{1}$ & 40 & 80 & 53 \\
\hline $\mathbf{2}$ & 60 & 87 & 73 \\
\hline $\mathbf{3}$ & 53 & 87 & 87 \\
\hline $\mathbf{4}$ & 47 & 73 & 73 \\
\hline $\mathbf{5}$ & 40 & 60 & 53 \\
\hline $\mathbf{6}$ & 53 & 73 & 73 \\
\hline $\mathbf{7}$ & 60 & 93 & 100 \\
\hline $\mathbf{8}$ & 73 & 87 & 80 \\
\hline $\mathbf{9}$ & 67 & 60 & 60 \\
\hline $\mathbf{1 0}$ & 40 & 67 & 67 \\
\hline $\mathbf{1 1}$ & 53 & 80 & 73 \\
\hline $\mathbf{1 2}$ & 40 & 87 & 73 \\
\hline $\mathbf{1 3}$ & 27 & 53 & 67 \\
\hline $\mathbf{1 4}$ & 60 & 80 & 53 \\
\hline $\mathbf{1 5}$ & 67 & 93 & 93 \\
\hline
\end{tabular}

Fonte: Dados da pesquisa (elaboração das autoras).

Na Tabela 7, nota-se que 13 alunos (87\%) aumentaram o número de acertos do pré-teste, comparando-se com o follow-up.

Na comparação do pós-teste com o follow-up, seis alunos (40\%) mantiveram o mesmo número de acertos e dois (13\%) aumentaram. 
Foi realizado um teste estatístico de medidas repetidas por meio do software SPSS, para a comparação do pré-teste, pós-teste e follow-up dos alunos. Os resultados indicaram diferenças estatísticas entre pré e pós-teste e entre pré-teste e follow-up.

\section{CONCLUSÃO}

O objetivo desse trabalho foi programar, aplicar e avaliar um software educativo para universitários com o tema de prevenção de AT. Em relação à programação, foram criadas as unidades de ensino, seguindo uma metodologia pedagógica. Essas unidades foram inseridas no programa de computador, também produzido especialmente para essa pesquisa, para que cada participante da ação educativa tivesse acesso a todas as unidades. Na aplicação da ação educativa, as informações dos alunos foram armazenadas e permitiram a geração de relatórios para avaliação. Nesse contexto, os objetivos foram atingidos, pois todos os procedimentos foram realizados com êxito.

Com a revisão da literatura sobre a investigação das principais causas de AT e pelo questionário inicial aplicado para levantamento de subsídios para a criação do software, optou-se pelo tema velocidade.

Os resultados obtidos, de forma quantitativa e qualitativa, trouxeram informações importantes, pois os universitários tiveram conhecimentos sobre AT e limites de velocidade que não sabiam.

No follow-up aplicado aos alunos do grupo experimental houve aumento significativo do número de questões corretas do pré e pós-teste e entre pré-teste e follow-up, identificando aprendizagem de conteúdos e sensibilização por parte dos alunos com os assuntos abordados.

Os alunos descreveram que os conteúdos das unidades, das instruções e dos feedbacks foram muito bons/bons, verificaram que as questões estavam de acordo com os conteúdos apresentados e identificaram que os perigos de correr em alta velocidade é responsabilidade de todos e que ações educativas podem diminuir o número de AT. 
É necessário enfatizar que, segundo levantamento da literatura, há escassez de trabalhos sobre esse assunto, especialmente voltados aos jovens universitários, o que torna de interesse os resultados deste trabalho, apesar da não generalização para a população, podendo ser um estudo sugestivo para replicações, a fim de comparação. Recomendam-se replicações em outras instituições com amostras maiores.

Concluiu-se que o software levou informações sobre AT, velocidade, leis e normas do trânsito, sendo avaliado de forma positiva pelos universitários. Além disso, a realização de atividades com prevenção de acidentes de trânsito mostrou-se viável em ambientes universitários com o uso de softwares educativos, contribuindo para que os motoristas possam identificar seu modo de dirigir a fim de que o número de AT seja reduzido, principalmente entre os jovens.

\section{REFERÊNCIAS}

ABREU, A. M. M. Mortalidade nos acidentes de trânsito na cidade do Rio de Janeiro relacionada ao uso e abuso de bebidas alcoólicas. 2006. Tese (Doutorado) Centro de Ciências da Saúde, Universidade Federal do Rio de Janeiro, Rio de Janeiro, 2006.

ANDRADE, S. M. et al. Comportamentos de risco para acidentes de trânsito: um inquérito entre estudantes de medicina na região sul do Brasil. Revista da Associação Médica Brasileira, São Paulo, v. 49, n. 4, p. 439-444, 2003. Disponível em: <http://www.scielo.br/pdf/ramb/ v49n4/18346.pdf>. Acesso em: 03 jun. 2009.

ASSOCIAÇÃO BRASILEIRA DE EMPRESAS DE PESQUISA. Critério de Classificação Econômica Brasil. ABEP, 2003. Disponível em: <http://www.abep. org/novo/Content.aspx?ContentID=302>. Acesso em: 26 fev. 2012.

BERNARDES, S. M. C. Algumas coisas que B. F. Skinner pode dizer a professores e estudantes de psicologia interessados em educação. In: TEIXEIRA, A. M. S. A. et al. (Org.). Ciência do comportamento: conhecer e avançar. Santo André: Esetec, 2002. v. 2.

BULHÕES, P. N. S. Avaliando o processo de ensino/aprendizagem: uma experiência com o estudo individualizado em cursos de graduação na UFRN. 2008.

Disponível em: <http://www.angrad.org.br/area_cientifica/artigos/ avaliando_o_processo_de_ensino_aprendizagem_uma_experiencia_com_o_ estudo_individualizado_em_cursos_de_graduacao_na_ufrn/584/>. Acesso em: 24 jul. 2009.

CATANIA, A. C. Aprendizagem: comportamento, linguagem e cognição. 4. ed. Porto Alegre: Artmed, 1999. 
CRONE-TODD, D. et al. The effect of changing grading criteria on student writing. Behavior Analyst Today, v. 8, n .1, p. 35-42, 2007.

CROSBIE, J.; KELLY, G. A computer-based personalized system of instruction course in applied behavior analysis. Behavior Research Methods, Instruments $\&$ Computers, v. 25, n. 3, p. 366-370, Sept. 1993.

FILATRO, A. Design instrucional na prática. São Paulo: Pearson Education do Brasil, 2008.

HÜBNER, M. M. C.; MARINOTTI, M. (Org.). Análise do comportamento para a educação: contribuições recentes. Santo André: Esetec, 2004.

KINSNER, W.; PEAR, J. J. Computer-aided personalized system of instruction for the virtual classroom. Canadian Journal of Educational Comunication, v. 17, n. 1, p. 21-36, 1988.

KOEN, B. V. Contingencies of reinforcement to maintain student progress throughout a web-based PSI course. 2001. Disponível em: <http://www.eecs. kumamoto-u.ac.jp/ITHET01/proc/037.pdf.>. Acesso em: 12 fev. 2010.

MAEDA, V. A. et al. Desenvolvimento de objetos de aprendizagem para o ensino a distância de geoprocessamento. In: SIMPÓSIO BRASILEIRO DE SENSORIAMENTO, 12., 2005, Goiânia. Anais... Goiânia, 2005. p. 1305-1312.

MARÍN-LEON, L.; VIZZOTTO, M. M. Comportamentos no trânsito: um estudo epidemiológico com estudantes universitários. Cadernos Saúde Pública, v. 19, n. 3, p. 515-523, mar./abr. 2003. Disponível em: <http://www.scielo.br/pdf/ csp/v19n2/15417.pdf >. Acesso em: 03 jun. 2009.

PAULO, A. Código de Trânsito Brasileiro. 10. ed. Rio de Janeiro: DP\&A, 2006.

PEAR, J. J.; NOVAK, M. Computer-aided personalized system of instruction: a program evaluation. Teaching of Psychology, v. 23, n. 2, p. 119-123, Apr. 1996.

PETERS, J.; PEDRYCZ, W. Engenharia de software. Rio de Janeiro: Campus, 2001.

PIVA, D.; FREITAS, R. L.; MISKULIN, R. G. S. Linguagem dialógica instrucional: a (re)construção da linguagem para curso online. In: CONGRESSO INTERNACIONAL ABED DE EDUCAÇÃO A DISTÂNCIA, 15., 2009, Fortaleza. Anais... Fortaleza, 2009. p. 1216-1224.

PRESSMAN, R. Engenharia de software. São Paulo: Makron Books, 2002.

SANCHO, J. M. Para uma tecnologia educacional. Porto Alegre: ArtMed, 1998.

SÃO PAULO (Estado). Departamento Estadual de Trânsito De São Paulo. Dicas de direção defensiva. São Paulo: Detran, 2009. Disponível em: <http://www. detran.sp.gov.br/renovacao/direcao_defensiva.asp>. Acesso em: 2 ago. 2009.

SÃO PAULO (Estado). Departamento Estadual de Trânsito De São Paulo. Alteração de categoria na CNH. São Paulo: Detran, 2001. Disponível em: <http:// www.detran.sp.gov.br/noticias/20060413a.asp>. Acesso em: 05 jun. 2011. 
SILVA, F. G.; DAGOSTIN, C. G. A relevância de produzir conhecimento social e científico sobre o comportamento humano no trânsito. Estudos de Psicologia, v. 11, n. 1, p. 115-118, jan./abr. 2006. Disponível em: <http://www.scielo.br/ scielo.php?script=sci_arttext\&pid=S1413-294X2006000100014\&lang=pt $>$. Acesso em: 05 jul. 2009.

SPRINGER, C. R.; PEAR, J. J. Performance measures in courses using computer-aided personalized system of instruction. Computers $\&$ Education, v. 51, n. 2, p. 829-835, 2008.

TEIXEIRA, A. M. S. A individualização do ensino em uma pré-escola: uma intervenção comportamental na educação infantil. In: TEIXEIRA, A. M. S. A. et al. (Org.). Ciência do comportamento: conhecer e avançar. Santo André: Esetec, 2002. v. 1.

VALENTE, J. A. Diferentes usos do computador na educação. 1993.

Disponível em: <http://nied.unicamp.br/publicacoes/separatas/Sep1.pdf>. Acesso em: 24 jul. 2009.

VALENTE, J. A. O computador na sociedade do conhecimento. Campinas: Unicamp/ Nied, 1999.

VARGAS, J. S. Como formular objetivos comportamentais úteis. São Paulo: EPU, 1974.

ZANOTTO, M. L. B. Formação de professores: a contribuição da análise do comportamento. São Paulo: Educ, 2000.

WILSON, C. et al. Speed cameras for the prevention of road traffic injuries and deaths. Cochrane the Cochrane Library, v. 11, 2010. Disponível em: <http:// www.update-software.com/BCP/WileyPDF/EN/CD004607.pdf.>. Acesso em: 12 set. 2014.

\section{ELAINE PASQUALINI}

Professora titular da Faculdade de Tecnologia de Ourinhos (Fatec Ourinhos), Ourinhos, São Paulo, Brasil

elaine.pasqualini@fatecourinhos.edu.br

\section{SANDRA REGINA GIMENIZ-PASCHOAL}

Professora do Programa de Pós-graduação em Educação e do Departamento de Fonoaudiologia da Universidade Estadual Paulista "Júlio de Mesquita Filho" (Unesp/Marília), Marília, São Paulo, Brasil sandragp@marilia.unesp.br 